\title{
MEMORIA, HISTORIA Y PATRIMONIO: HACIA UNA CONCEPCIÓN SOCIAL DEL PATRIMONIO
}

\author{
MEMORY, HISTORY AND HERITAGE: TOWARD A SOCIAL CONCEPT OF THE HERITAGE
}

MATILDE GONZÁLEZ MÉNDEZ (*)

A ella, que me acompañó permanentemente mientras redactaba

\section{RESUMEN}

Se explora la noción de Patrimonio Arqueológico y su relación con la más amplia de Pasado. Para ello se analiza cómo funciona el pasado y sus vestigios en tres formaciones socioculturales con patrones de racionalidad diferentes: el de las sociedades primitivas, el de las sociedades campesinas tradicionales y el de la sociedad moderna.Aunque esta revisión es sucinta, intentamos ver cómo ambos conceptos se integran en la práctica cotidiana de la arqueología de cara a aunar y compatibilizar teoría y práctica arqueológica.

\begin{abstract}
This work explores the notion of Archaeological Heritage and its relationship with the wider concept of the Past. For this we look at three social formations and see how the past and its remains work within them. They are: primitive societies, peasant societies and modern society. Although both concepts are revised in a brief way, we will attempt to see how both are integrated within the day-today work of archaeology, in order to combine archaeological theory and practice.
\end{abstract}

Palabras clave: Teoría arqueológica. Patrimonio Arqueológico. Transmisión cultural. Revalorización del patrimonio.

Key words: Archaeological theory. Archaeological Heritage. Cultural transmission. Revaluation of the heritage.

(*) Grupo de investigación en Arqueología del Paisaje, Laboratorio de Arqueología y Formas Culturales. Instituto de investigaciones Tecnológicas. Edificio Monte da Condesa, Campus Sur, Universidad de Santiago de Compostela. 15706. Santiago de Compostela. Correo electrónico: pharpa@usc.es

El artículo fue remitido en su versión final el 28-IX-2000.

\section{LOS MÓVILES}

Esta exploración parte de la constatación de diversas circunstancias relacionadas con la gestión y revalorización de los bienes arqueológicos, circunstancias que en aras de la brevedad sintetizamos en (1) el hecho de que los restos arqueológicos atraen y (2) en que no existe una clara noción de lo que es el patrimonio arqueológico.

\subsection{El atractivo de los bienes arqueológicos}

Hoy la atención hacia los bienes arqueológicos es creciente; los móviles que la sustentan tan diversos como los sectores sociales que con ellos se relacionan. Desde un punto de vista general se pueden distinguir tres grandes grupos: los gobiernos, los profesionales de la arqueología, y los ciudadanos en general. Para cada uno de ellos el atractivo del vestigio arqueológico se sitúa en aspectos distintos.

Los gobiernos reconocen su papel de: recurso dinamizador de zonas geográficas retraídas, sustentador de la población en áreas rurales donde la agricultura no resulta productiva, impulsor de nuevas áreas de empleo en una sociedad en la que los servicios serán el principal sector de nueva actividad, soporte de identidades (nacionales y supraestatales) y coagente de la calidad de vida en el marco del desarrollo sostenible.

Sobre tales bases los políticos persiguen, sobre todo, su utilidad socioeconómica y su capacidad de aglutinador identificador social.

A los técnicos los restos arqueológicos nos cautivan, para decirlo de forma escueta, por la posibi- 
lidad que ofrecen de indagar sobre el pasado y la persona. Sobre la premisa, harto repetida, de que son bienes culturales que ilustran el pasado de la humanidad y, la no siempre reconocida, de que son condición básica de nuestra existencia como profesionales, demandamos su gestión y mantenimiento.

Sabemos que su conservación depende del papel que juegan en la sociedad porque en función del alcance que en ella posean se le destinan más o menos recursos. Así los profesionales tratamos de que los bienes arqueológicos atraigan al público.

La ciudadanía parece inclinarse hacia los bienes arqueológicos por dos motivos principales: ocio y negocio. Desde hace tiempo sus cualidades (antigüedad, belleza, posibilidad de identificación con un pasado...) atraen a una minoría de devotos. Hoy, con más formación y tiempo libre que hace unos lustros, además pueden entretener a muchos, pues en sus actuales formas de presentación in situ los vestigios se imbrican muy bien con el turismo alternativo y el ocio activo.

Un segundo factor de interés es la generación de actividad económica en el sector de los servicios educativos y recreativos. Así lo muestra el surgimiento de pequeñas empresas privadas y servicios de laAdministración relacionados con la educación no reglada, las actividades culturales, de tiempo libre, las rutas guiadas... (1).

Todos estos intereses permiten decir que si la arqueología es resultado de la voluntad de poder, de justificar en el pasado la existencia presente (Criado, 1989a), hoy las necesidades sociales de consumo cultural y las posibilidades de actividad económica han engendrado una nueva forma de entender el vestigio arqueológico. Frente a la tradicional concepción de monumento o documento que sobre todo debe ser estudiado y preservado, actualmente se concibe como objeto de uso, de disfrute social. Por eso su clásico papel estático ha ido transformándose hasta convertirse en eficaz recurso dinamizador de la cultura y la economía.

En tal contexto se entiende el buen momento que parece vivir la revalorización de bienes arqueológicos con numerosos proyectos y actuaciones en todo el Estado y un creciente número de publicacio-

(1) Es muy ilustrativo el caso de un paisano de Calatañazor (Soria) que, viendo la afluencia de turistas al pueblo, decidió confeccionar un "museo" misceláneo en su casa. Al precio de la voluntad, que del viajero en vacaciones puede ser generosa, ofrece la contemplación de elementos etnográficos y arqueológicos. nes (2). Pero, a pesar de tal actividad, falta cierta reflexión (en el origen, objetivos, procedimiento y resultados de tales actuaciones) que permita armonizar, entre profesionales, bases de acción para ordenar y programar el presente y futuro del sector.

Una de estas carencias se advierte en la comprensión de nociones como pasado o patrimonio arqueológico; aunque parezcan simples cuestiones terminológicas de su entendimiento derivan desde el destino de los recursos hasta la propia organización de la gestión. Por eso nos propusimos explorarlas $y$, en función del espacio disponible, lo haremos de forma reflexiva más que práctica o normativa (3).

\subsection{La idea imprecisa de patrimonio arqueológico}

Los bienes arqueológicos se identifican con patrimonio arqueológico (en adelante PA) y éste con patrimonio histórico o cultural (4). El patrimonio cultural (y cada uno de los ámbitos que integra) se define como el legado histórico y social del pasado que pervivió a lo largo del tiempo y que es preciso conservar para generaciones futuras. Sin embargo, no existe una clara idea de cómo se concreta esa herencia social, cómo o qué se debe preservar, porqué se preserva.

Desde el punto de vista legal la línea que orienta la noción de patrimonio en textos normativos es la alusión a la cultura y a la historia como elementos definidores. Así por ejemplo, en las leyes españolas (5) los valores artísticos, históricos, arqueológicos (6), técnicos, etc. establecen el punto a partir del cual un elemento queda amparado como patrimonio. Sin embargo, las normas no concretan

(2) Sólo monográficos y en los dos último años se pueden citar las siguientes revistas: Cota Zero, 15 (1999); Museo, 4 (1999); Boletín del Instituto Andaluz del Patrimonio Histórico, 25 (1998); Treballs D'Arqueologia, 5 (1998).

(3) Se espera con ello que el lector pueda extraer sus propias consecuencias para la acción.

(4) A partir de aquí cuando utilicemos los términos más generales de patrimonio histórico, patrimonio cultural, o incluso patrimonio sin calificativo adjunto, se entenderá que estos términos más genéricos incluyen al PA y que éste participa de las mismas circunstancias a las que se refiere el comentario.

(5) Como es la Ley 16/85, de 25 de junio, de Patrimonio Histórico Español; la Ley 1/1991, de 3 de julio, de Patrimonio Histórico de Andalucía; la Ley 8/1995, de 30 de octubre, de Patrimonio Cultural de Galicia, etc.

(6) Se entiende que el PA posee este valor aunque las leyes españolas lo definen también en función de la metodología de trabajo. Una discusión más amplia sobre los criterios legales para delimitar el PA se ofrece en González (2000: 385-387) y en Querol y Martínez (1996: 39-41).

T. P., 57, n. ${ }^{\circ} 2,2000$ 
qué son estos valores adjetivados con calificativos que, en última instancia, se refieren a la cultura en un sentido amplio (Barrero, 1990: 113 y ss.); tampoco cuándo un elemento los posee. De hecho, las leyes hablan de la naturaleza jurídica de los bienes que integran el patrimonio, no de sus cualidades culturales (Alegre, 1994: 645-647; Barrero, 1990: 257-317). Esto es insuficientemente valorado por muchos profesionales del patrimonio que reprochan a las leyes la inconcreta o incompleta definición de patrimonio, o de PA, cuando al cuerpo legal le toca ordenarlo mientras que delimitarlo es más bien tarea de los profesionales (7).

Las nociones técnicas no son mucho más precisas; después de analizar casi una veintena de definiciones apuntadas por profesionales (González, 1999: 150-157) vimos que la noción de patrimonio gira en torno a tres ideas: (1) como en las leyes la cultura e historia son'elementos determinantes de la naturaleza del patrimonio; (2) la doble dimensión, material e inmaterial, del patrimonio siendo la segunda, la inmaterial, la fundamental en su conformación pues lo material, los bienes, es sólo el soporte de lo inmaterial, las ideas y nociones que sobre el pasado sustentan esos bienes; (3) el legado patrimonial posee gran valor aunque para algunos éste es intrínseco al bien mientras que otros piensan que sólo lo adquiere cuando el receptor se lo otorga.

Aunque más ajustadas a la naturaleza del patrimonio, estas ideas no encajan muy bien con el tratamiento cotidiano que reciben los bienes arqueológicos. Llama, por ejemplo, la atención que proclamemos la importancia de esta herencia cultural cuando para el conjunto social el PA apenas tiene trascendencia. Esto se ve ante hechos como el barrido de bienes por el desarrollo urbanístico con el apoyo tácito o explícito de la población, la queja generalizada de que se destruye si laAdministración competente no lo impide o que ningún sector económico se toma el patrimonio histórico en serio, ni bancos, ni construcción, ni tan siquiera las Cajas de Ahorros cuyas fundaciones culturales invierten en otros sectores más rentables: arte, música... (Antona, 1994; Querol et alii, 1995: 241) (8).

(7) Un extenso análisis de las definiciones normativas se ofrece en González (1999).

(8) La falta de inversiones no ha sido paliada por la nueva normativa de Mecenazgo (Ley 30/1994, de 24 de noviembre, de Fundaciones y Mecenazgo y R. D. $765 / 1995$ por el que se regulan los incentivos fiscales a la participación privada en actividades de interés general) reiteradamente calificada de insuficiente por sus escasos incentivos y su gran intervencionismo administrativo (Duralde, 1995: 36; Barril, 1996: 322; Costa et alii, 1996: 371; Querol y Martínez, 1996: 373; Álvarez, 1997: 23).

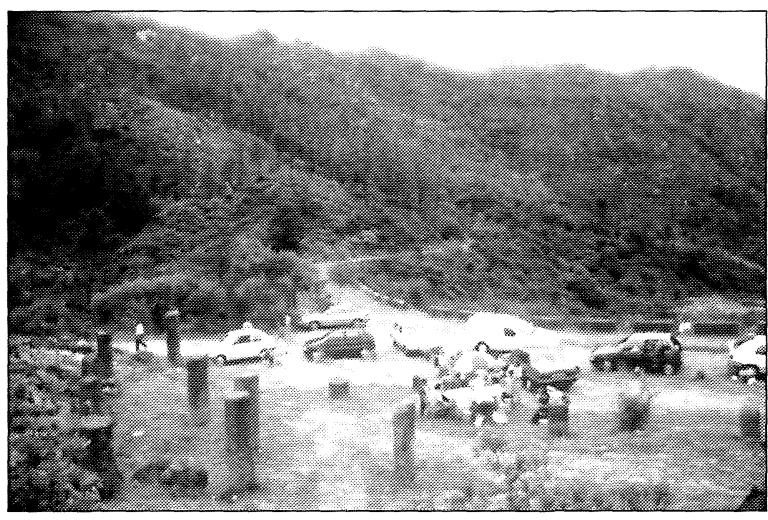

Lám. I. El Patrimonio Arqueológico poco interesa a la sociedad. Miliarios de la vía XVIII (Itinerario de Antonino) reunidos en un punto de la vía y sirviendo de marco a una comida campestre.

Los que reconocen que el PA poco interesa a la sociedad son múltiples (Antona, 1994; Querol et alii, 1995: 244; Querol y Martínez, 1996: 352) (Lám. I). Por eso, hemos de reconocer que la noción de patrimonio manejada en el ambiente legal y profesional no se ajusta del todo a la realidad, al menos a la de nuestro Estado. Hay algo que falla en ella cuando la evidencia es que para la generalidad de la población, incluso para algunas instancias públicas, el PA no es herencia valiosa, sino residuo de la historia en ocasiones fácilmente llevadero pero otras realmente molesto. Todo esto fue lo que nos llevó a indagar sobre la noción de patrimonio y su relación con el pasado.

\section{LA EXPLORACIÓN}

Son muchos los que afirman la carencia de significación social del PA (Merriman, 1988: 146-147; Shanks y Tilley, 1987: 8; Tilley, 1989: 109; Cleere, 1989: 5-6). La causa generalmente aludida es que en la sociedad occidental actual el pasado (9) está desconectado del presente, es algo acabado, muerto. Utilizando la metáfora de Lowhental (1998) el pasado se ha convertido en un extraño país (10). Si como muchos profesionales sostienen

(9) Pasado no es sinónimo de patrimonio pues la acepción de pasado es más amplia (incluso con referencia a la historia y lo histórico). Pero, dado que patrimonio se entiende como "herencia del pasado", utilizaremos el término como semejante de PA. Es una licencia discursiva que solicitamos se nos consienta para evitar la reiteración de PA.

(10) Metáfora que sirve de título a la publicación en la que se realiza un interesantísimo examen de los mecanismos que ac- 
el PA es expresivo de los valores que una sociedad otorga a su pasado remoto, hemos de considerar que la ruptura con un pasado más allá del inmediatamente próximo, esto es, más allá del comienzo de la industrialización y de la descomposición de las sociedades campesinas y tradicionales con las que aún podemos tener algún tipo de nexo (con ellas y con sus restos materiales) permite explicar, al menos en parte, actitudes de ignorancia, indiferencia o incluso aversión. Si el presente se ha emancipado del pasado, los valores que éste encarna y los elementos en que se materializa pueden también alejarse de nuestra experiencia cotidiana.

Este argumento puede explorarse recurriendo a diversas formaciones sociales y viendo cómo funciona en ellas el pasado, la tradición social (11) y otros ámbitos que conforman la noción de patrimonio. No se trata de hacer una historia evolutiva ni causal del PA en el sentido de la historia positiva tradicional. Nuestro intento se asemeja más a un análisis genealógico como Foucault (1981: 128-45; 1985) lo entiende y aborda aunque sin llegar a la profundidad que este tipo de análisis requiere. Por eso nos ceñiremos a ilustrar una geología del PA, es decir, a mostrar algunos de los estratos sobre los que se asienta su actual noción. Estas capas se conformarán a partir de la visión del pasado y sus vestigios por parte de tres patrones de racionalidad: el de las sociedades primitivas, el de sociedades campesinas tradicionales y el de la sociedad moderna (12).

\subsection{Las sociedades primitivas, el pasado como presente}

Para no detenernos en un tema trillado por la antropología entenderemos por sociedades primitivas los grupos de cazadores-recolectores o agri-

tualmente intervienen en la producción de pasado, de las razones que llevan a buscar ese pasado y de los beneficios que reporta.

(11) Entendida igual que Goody y Watt (1996: 39 y ss.) como memoria social a través de la cual una generación transmite su acervo cultural a la siguiente. Así, la tradición social puede definirse como el conjunto de conocimientos y valores que permiten pensar y crear lo real: desde las ideas de tiempo y espacio hasta el modo de entender el medio. Esto viene a ser lo que LeviStrauss (1964; 1987: 35-42) designa pensamiento o lo que Foucault (1985: 31-46 y 127-62;1988a, b) llama sistema de saber-poder o lo que Criado (1993: 20) denomina modelo de racionalidad que poseen todas las formaciones sociales.

(12) Nuestra exposición se compondrá con niveles de la realidad empírica y conceptual a veces no suficientemente caracterizados pero que permiten ilustrar nuestro argumento. Con seguridad no están todas las formas de pensamiento que fueron y son en la humanidad pero las que están manifestarán cómo funciona el pasado y sus vestigios en distintas sociedades. cultores tempranos situados en los dominios del pensamiento salvaje según lo define Lévi-Strauss (1964) y cuya determinación más específica, siguiendo a Clastres (1996), es ser sociedades sin Estado, indivisas y homogéneas en su ser (13).

Para lo que aquí interesa, se puede decir que las sociedades primitivas son sociedades sin pasado puesto que intentan ocultar y negar los efectos del tiempo y los cambios que en su transcurso se producen. Aunque no lo logran del todo, pues toda sociedad cambia con el tiempo, su intento es permanecer iguales a sí mismas negando la diacronía. Entre su origen mítico y su presente, no hay más que tiempo vacío de significado. Tienen un antes y un después, pero uno no es más que el reflejo del otro (Levi-Strauss, 1964: 339-41) (Tab. 1) (14).

Las sociedades primitivas son ágrafas. Su legado cultural se transmite a través de lapalabra lo que

\begin{tabular}{|l|l|}
\hline \multicolumn{2}{|c|}{ SOCIEDAD PRIMITIVA } \\
\hline Tiempo & $\begin{array}{l}* \text { No hay sentido del tiempo } \\
\text { Negación de su devenir y sus } \\
\text { efectos }\end{array}$ \\
\hline Espacio & $\begin{array}{l}* \text { Fuerte sentido del espacio po- } \\
\text { blado de valores culturales: } \\
\text { paisaje } \\
\text { Identificación y equivalencia } \\
\text { con la sociedad }\end{array}$ \\
\hline Transmisión cultural & $*$ Oral \\
\hline Valores & $\begin{array}{l}* \text { Conservacionistas. La estabili- } \\
\text { dad como valor positivo }\end{array}$ \\
\hline Discurso sobre el pasado & $*$ Ninguno \\
\hline
\end{tabular}

Tab. 1. Ilustración de aspectos sociales y culturales de la racionalidad primitiva así como la significación del pasado y sus vestigios en el entramado que tales aspectos configuran.

(13) Desde la exploración de diferentes trabajos antropológicos, F. Criado (1989b, 1993) ha compuesto una caracterización de estas sociedades que nos permitirá adjetivarlas de forma sintética. Tal caracterización se desarrolla con detalle en su tesis doctoral Contribución al estudio de las relaciones entre las comunidades megalíticas del Noroeste peninsular. Universidad de Santiago de Compostela, Departamento de Historia 1, 1989.

(14) Dos ámbitos donde mejor puede advertirse la relación presente-pasado y la concepción del tiempo son el mito y la muerte (Criado, 1989b). Respecto a la muerte, las sociedades primitivas discriminan entre los antepasados, muertos recientes a los que se trata de olvidar pues muestran el discurrir del tiempo, y los ancestros, muertos antiguos situados en un tiempo anterior al tiempo, protagonistas de los mitos y definidores de las normas que rigen la sociedad (Clastres, 1996: 74-86). En cuanto a los mitos, explicación del universo material y espiritual en el que se desenvuelve el grupo (Levi-Strauss, 1991: 577) una de sus finalidades es asegurar que el futuro permanecerá igual que el presente y pasado (Levi-Strauss, 1986: 65); se desarrollan en un tiempo anterior al tiempo (tiempo mítico) y definen los orígenes de la sociedad y el conjunto de reglas que la organizan. 
tiene un efecto particular sobre la transmisión cultural y sobre nociones como cambio y devenir (15). Una de sus especifidades es que su legado social se funda en la memoria colectiva que, al igual que la individual que es incapaz de recordar toda nuestra experiencia, mantiene un equilibrio constante entre el recuerdo y el olvido.

A través de la palabra (en mitos, normas de comportamiento, etc.) se incorpora al recuerdo social lo que es importante en la experiencia de la comunidad, al tiempo que se olvida lo que no interesa. Así, se recuerda, se acumula en la experiencia, lo útil (tanto material como espiritualmente) mientras que se olvida aquello que no lo es. Este proceso conlleva cambios en el saber social pero la transmisión oral no permite verificarlos. La ausencia de escritura hace muy difícil contrastar versiones viejas y nuevas, pues las innumerables mutaciones que surgen en el discurso oral se incorporan espontáneamente sin que tales cambios se perciban con facilidad (Goody y Watt, 1996: 42 y ss.) (16).

Uno de los resultados de tal equilibrio entre recuerdo y olvido que Goody y Watt (1996) califican de tendencia homeostática es que el individuo no tiene mucha percepción del pasado sino es en función del presente. Así, sostienen que la conciencia del pasado depende de una sensibilidad histórica que difícilmente puede darse sin registros escritos permanentes (Goody y Watt, 1996: 46).

De otra parte, interesa decir que uno de sus valores primordiales, como comunidad social, es el de la estabilidad, el intento de mantener invariables sus condiciones de vida, por eso reniegan del cambio como realización social positiva. Viven en comunión con la naturaleza de donde deriva su profundo conocimiento del entorno y su gran sentido territorial a través del que cada comunidad se identifica frente a las vecinas. De hecho, a diferencia del tiempo, el espacio está poblado de significado (17).

(15) La oralidad y sus efectos en la transmisión cultural ha sido ampliamente estudiada por J. Goody $(1985 ; 1987 ; 1996$; 1999) a quien seguimos para el desarrollo de este epígrafe.

(16) Un ejemplo son los mitos de los que la bibliografía ofrece numerosos ejemplos del surgimiento de versiones modificadas y adaptadas a las circunstancias actuales de la comunidad sin que tales cambios se perciban, pues al no estar consignados por escrito resulta imposible contrastar una versión anterior con una posterior.

(17) En Levi-Strauss (1964: 241-2), se ofrecen ejemplos de geografía mítica y topografía totémica. En Mamami (1989: 56-7), se muestra como la palabra aymara pacha se refiere a un tiempo específico, a estaciones del año relacionadas con tareas agrícolas y con diferentes localizaciones espaciales y también designa una orientación espacial.
Con una concepción del tiempo que niega la diacronía olvidándose del pasado, la estabilidad como valor y una transmisión oral que actualiza, cada vez que las verbaliza o relata, las ideas y saberes de las generaciones anteriores es difícil interesarse por el pasado y sus restos. Así, esta exposición, aunque sintética, permite apuntar que en las sociedades primitivas el pasado y sus vestigios están incluidos en el presente porque la categoría de pasado no existe como tal. Para ellas el pasado es tiempo y espacio mítico y sus restos no son marcas del devenir histórico sino puntos que permiten cerrar la circularidad del tiempo, su recurrencia. Estando el pasado vacío de significado, el patrimonio histórico no existe (González, 1999: 170-180).

\subsection{Las sociedades tradicionales, el pasado como la huella de 'los otros'}

Entre la inexistencia de un patrimonio, porque aún no hay pasado, en las sociedades primitivas, $y$ la actualidad en la que se proclama como resto de nuestro 'pasado', se pueden entrever otras racionalidades como la de las sociedades campesinas tradicionales (Tab. 2).

\begin{tabular}{|l|l|}
\hline \multicolumn{2}{|c|}{ SOCIEDAD CAMPESINA Y TRADICIONAL } \\
\hline Tiempo & $\begin{array}{l}* \text { Se asume su discurrir pero no } \\
\text { hay profundidad temporal }\end{array}$ \\
\hline Espacio & $\begin{array}{l}* \text { Gran conocimiento del espacio } \\
\text { utilizado e ignorancia del resto } \\
\text { * Identificación con territorio }\end{array}$ \\
\hline Transmisión cultural & $*$ Oral/Escrita \\
\hline Valores & $\begin{array}{l}* \text { Conservacionistas. Apego a la } \\
\text { tradición } \\
\text { El cambio como valor negativo }\end{array}$ \\
\hline Discurso sobre el pasado & $\begin{array}{l}* \text { El tiempo como tradición } \\
\text { Historia del 'Otro' }\end{array}$ \\
\hline $\begin{array}{l}\text { Significación/utilidad del } \\
\text { Patrimonio }\end{array}$ & $\begin{array}{l}* \text { Refuerzo de la identidad cul- } \\
\text { tural }\end{array}$ \\
\hline
\end{tabular}

Tab. 2. Ilustración de aspectos sociales y culturales de la racionalidad campesina así como la significación del pasado y sus vestigios en el entramado que tales aspectos configuran.

Wolf (1982: 5) define a las sociedades campesinas como "esos amplios sectores de la humanidad que se encuentran entre la tribu primitiva y la sociedad industrial. Esas poblaciones que abarcan muchos millones de individuos, ni primitivos ni modernos...". Tal definición, aunque algo vaga, per- 
mite marcar los límites de estas sociedades al tiempo que mostrar su amplia diversidad.

Tomando una caracterización socio-económica de Vicent (1990: 274-277), se podrían determinar a partir de la vinculación permanente del productor con el medio de producción (en este caso la tierra). Esto implica que pueden convivir, en muy diversas formas y situaciones, en diferentes formaciones económico-sociales e intervenir en distintos modos de producción. Aunque tampoco poseen una situación geográfica y temporal concreta, en función de los datos que aquí manejamos nos referiremos a las comunidades agrarias desarrolladas en Europa desde la Edad Media, anteriores a la mecanización e industrialización del campo que, aunque forman parte de una sociedad más compleja (nacional o estatal) con la que mantienen una cierta relación de dependencia político-económica y cultural, poseen un alto grado de autosuficiencia e independencia en su actividad económica, social y cultural y a lo que aquí interesa se caracterizan por:

- Poseer un profundo conocimiento de su entorno del que obtienen diversos tipos de recursos según los diferentes nichos ecológicos.

- Detentar fórmulas de posesión de la tierra, de trabajo y de sociabilidad colectivas.

- Ser iletradas aunque interaccionen con la cultura letrada dominante. Se puede decir así, que son culturas ágrafas en el seno de culturas letradas (18).

Son grupos con fuertes valores comunitarios y lazos de solidaridad expresados en fórmulas de trabajo colectivo o ceremoniales en los que participa toda la comunidad. Aunque diferencian entre presente y pasado, sus nociones temporales son fragmentarias, confusas y sin una profundidad ordenada. Si bien admiten el cambio, este es aún un valor negativo (Dumont, 1989) y poseen un carácter conservador manifiesto en la resistencia a variar en cualquier ámbito de lo cotidiano.

Su relación con el espacio es compleja y contradictoria, pues conocen muy bien el espacio que usan pero se mantienen de espaldas al resto. De hecho, lo que más resalta de la relación de los campesinos con el espacio es su constitución como territorio, pues la apropiación de la naturaleza se hace en forma de una reclamación efectiva de los derechos sobre la tierra (Criado, 1988; 1993). Con todo, las sociedades campesinas tienen un gran conocimiento del medio que utilizan, mantienen una in-

(18) En este sentido también se las denomina culturas populares (Llinares, 1990a). tensa relación con él y perciben, entre otras cosas, las huellas de la actividad humana anterior en el tiempo.

Tal modo de ser en gran medida ha desaparecido del ámbito europeo por la implantación de nuevas formas de vida, pero pueden rastrearse evidencias de él en zonas donde la industrialización del campo fue tardía como es el caso de Galicia (19). Veamos como funcionan aquí los vestigios.

En Galicia, la sociedad campesina tradicional tiene incluidos a los elementos arqueológicos en su tradición oral a través del folclore, aunque la integración se hace ya a partir del reconocimiento de un corte temporal y cultural entre los constructores y moradores de estos vestigios, y los antepasados de la comunidad (Criado, 1986; Llinares, 1990b).

De acuerdo con este folclore, los restos arqueológicos perceptibles en el paisaje son obra de los mouros, individuos que ocuparon el territorio en un tiempo mítico del que los campesinos no tienen memoria. Los mouros no se perciben como antecesores de los actuales campesinos ya que, además de ser de otra raza, presentan características no humanas (la habitación bajo la tierra o el agua, la posesión de propiedades mágicas, etc.) y ocupan, no el tradicional espacio culturizado en el que se desenvuelve la actividad cotidiana, la casa y su entorno cultivado, sino un espacio menos humanizado, el monte, zona en la que se obtiene cierto aprovechamiento pero que no se cultiva. Esta alteridad de los mouros y de sus obras, constituye el desencadenante de un discurso del grupo sobre sí mismo en el que su identidad queda afirmada frente a la alteridad de los mouros (Llinares, 1990b: 21) (20).

Así puede notarse que en las sociedades campesinas tradicionales ya se admite el pasado más antiguo cuyos restos se integran en el presente social no como un continuo, sino marcando una discontinuidad entre los autores de los vestigios y la comunidad campesina actual. Esto refuerza la identidad cultural del grupo y hace significativo al espacio de algo más que del mero aprovechamiento económico (González, 1999: 180 y ss.).

(19) La cultura popular gallega se inscribe en un marco más extenso que abarcaría, al menos, a la Europa occidental. Sin llegar a mantener la total homogeneidad de estas culturas populares, existe un "aire de familia", una concepción similar (ciertos elementos que conforman el imaginario gallego: tesoros, mouros, trasnos, mujeres encantadas...) en todas ellas (Llinares, 1990a: 51). Así el ejemplo gallego ilustra esta generalidad.

(20) Esto puede verse en otras zonas como la Inglaterra me dieval y moderna donde los restos del pasado se explican, a través del folclore, como obra de gigantes y hadas que esconden tesoros (Darvill, 1993: 4-7), algo similar a los mouros gallegos. 
¿Cómo se disgrega este discurso de la «otredad» en torno a los vestigios del pasado y da paso a lo que nos encontramos en la sociedad occidental de hoy: un discurso científico del que participan unos pocos, que interpreta al PA como la huella del 'nosotros'?

\subsection{La sociedad moderna, el pasado como nues- tras raíces}

Será con la modernidad del siglo XIX y su proyecto de estudio del Hombre cuando la arqueología y la historia desarrollarán el discurso científico que otorga a los restos del pasado carácter de documento. A ello contribuyeron el historicismo y positivismo decimonónicos que alzaron al vestigio a la categoría de documento de la Historia y a ésta a la categoría de memoria del pasado. También la necesidad de legitimación de los Estados-nación que encontraban en los vestigios la huella palpable de una identidad cultural diferenciada. En este entramado, el bien arqueológico, como documento del pasado y símbolo de la nación, se convierte en instrumento material de la memoria y por tanto algo precioso a conservar (Bermejo, 1987: 31) (Tab. 3).

\begin{tabular}{|l|l|}
\hline \multicolumn{2}{|c|}{ SOCIEDAD MODERNA } \\
\hline Tiempo & $\begin{array}{l}* \text { Asunción del devenir y visión } \\
\text { positiva del mismo }\end{array}$ \\
$\begin{array}{l}\text { Noción lineal con profundidad } \\
\text { temporal estructurada }\end{array}$ \\
\hline Espacio & $\begin{array}{l}* \text { Visión totalmente utilitaria y } \\
\text { económica }\end{array}$ \\
\hline Transmisión cultural & $*$ Escrita-eidética \\
\hline Valores & $\begin{array}{l}* \text { Progresistas, individualismo, } \\
\text { bienestar... }\end{array}$ \\
\hline Discurso sobre el pasado & $\begin{array}{l}* \text { Tiempo como evolución } \\
\text { Historia del 'nosotros' }\end{array}$ \\
\hline $\begin{array}{l}\text { Significación/utilidad del } \\
\text { Patrimonio }\end{array}$ & $\begin{array}{l}* \text { Creación de una cadena tempo- } \\
\text { ral que se pretende cultural } \\
\text { Actualmente también econó- } \\
\text { mica }\end{array}$ \\
\hline
\end{tabular}

Tab. 3. Ilustración de aspectos sociales y culturales de la racionalidad moderna así como la significación del pasado y sus vestigios en el entramado que tales aspectos configuran.

Para llegar a esta concepción fue preciso recorrer un camino iniciado en el Renacimiento, momento en que se vio que el pasado era algo distinto del presente y sus vestigios significativos como testimonios de ese pasado. Asimismo, serían esencia- les acontecimientos como el descubrimiento de América, que demandó reinventar la imaginación para hacer pensable el mundo, pues a partir de él aparece un espacio indefinido y un tiempo inclasificable (Lorite, 1995: 21). También la imprenta, que permite la transmisión cultural a través del espacio y del tiempo hasta límites impensables. En este ambiente de novedad se inicia el camino de una modernidad definitivamente establecida a finales del siglo XIX y caracterizada por rasgos como:

- La ruptura con la tradición; el pasado, ancestralmente modelo a imitar, se convierte en pauta a superar. Así se entiende el fuerte sentido de discontinuidad temporal en el que el ordenamiento cronológico y lineal del pasado permite mostrar el cambio continuo de la humanidad.

- El cambio, ahora con un valor positivo, como Progreso, conducido por la Razón, se convierte en móvil del devenir histórico; la arqueología y la historia serán fuentes ilustradoras, los vestigios sus sólidos testigos. Por eso no es casual que surja ahora la necesidad de preservar los restos de una forma más expresa que antes, y que esta preservación adquiera la forma de un programa público de acción, con leyes, dotación de medios y la colocación de éstos en un entramado institucional: museos, universidad... (Tilley, 1990: 17 y ss.).

A partir de aquí, el discurso científico (arqueológico) de una élite formada y culta, desarrolla una significación de los restos del pasado que paulatinamente sustituye al discurso de las sociedades tradicionales. Esta explicación, asociada a los aspectos más irracionales y a-científicos de la cultura popular, desaparecerá progresivamente bajo la instrucción reglada a la que son sometidos los ciudadanos, por la aparición de los modernos medios de comunicación y por el cambio en las formas de relación con el medio social, cultural y natural, por la pérdida del sentido del lugar.

En efecto, el proceso de individuación, paulatino pero constante, del mundo moderno tuvo un importante papel. Circunstancias como la atomización familiar o la dejación de gran parte de la educación y socialización de la infancia en manos de profesionales ajenos a la familia, posibilita la disminución de las referencias socioculturales de la comunidad local.

Los nuevos modos de aprehensión del conocimiento y transmisión cultural, ahora fundamentalmente letrado, los nuevos modos de comunicación, ahora de masas, la emigración a la ciudad, etc., son mutaciones que facilitan aún más este proceso de 
pérdida de referentes que sólo se recuperarán a través de la educación reglada, de la transmisión textual, no anónima pero sí ajena al receptor. Igualmente, la estandarización de los modos de vida (el ideal moderno de progreso universal hacia un fin único e igual para toda la humanidad) ha tenido un peso específico importante.

Asimismo, la pérdida del sentido del lugar tuvo más efecto de lo que nuestra miserable concepción espacial (fundamentalmente económica y no social) nos permite pensar. De hecho, hasta ahora hemos hablado de pasado, o de cómo las huellas del tiempo se integran o no en lo cotidiano de las sociedades mientras que hemos ignorado el espacio cuando, como ha notado Criado (1988: 67), la dimensión fundamental del pasado y de sus vestigios, el patrimonio, es espacial pues "una cultura humana no es primeramente una sociedad en el tiempo, sino que es ante todo una sociedad en el espacio" (21). Las sociedades preindustriales dan buena muestra de ello con una fuerte vinculación (física y espiritual) a su entorno espacial, significativo en múltiples sentidos.

Este sentido del lugar se ha debilitado en las sociedades desarrolladas, que mantienen una total desvinculación con su entorno. Tal hecho, paralelo y concomitante con la desconexión entre presente y pasado, ampliamente comentado en la bibliografía anglosajona (Craig, 1989: 107-12; Lowhental, 1981: 215 y ss.; Saunders, 1989: 153; Walsh 1992: 11-12 y 148-159; 1995), en España ha pasado prácticamente desapercibido hasta muy recientemente (22), razón por la cual aquí es un tema aún no valorado. Los desencadenantes de este fenómeno de pérdida de significación del espacio son múltiples (González, 1999: 185):

- La falta de contacto con la tierra, con el medio, que, cada vez más se recorre, aprovecha o percibe menos directamente para hacerlo a través de la máquina (el tractor, el coche...). Con ello acabamos por comprender nuestro entorno como un espacio anodino en el que se desarrolla la actividad o el trabajo humanos.

(21) Por eso la concepción del tiempo va asociada a una semantización del espacio. Otra cosa es que, en nuestra cultura, la primacía del tiempo sobre el espacio traslade la comprensión de los fenómenos espaciales a coordenadas temporales. Aún así, el conocimiento histórico necesita utilizar una noción de espacio para ordenar los hechos a lo largo del tiempo.

(22) Una de sus primeras salidas a la luz, sino la primera, fue en el IV Congreso de Interpretación Global del Patrimonio celebrado en Barcelona en 1995. El subtítulo de este congreso era "sentido de identidad, sentido de lugar".
- Los cambios constantes del medio habitacional, sobre todo urbano, pues la alteración y reconstrucción incesantes eliminan referentes espaciales, símbolos de nuestras propias vivencias: la vieja casa, el antiguo quiosco...

- La emigración y la movilidad que vuelve habituales los desplazamientos.

- El propio concepto de espacio manejado en el que priman los componentes jurisdiccionales y económicos (Criado, 1988), no históricos o sociales.

El resultado de esto es no es sólo la merma de la percepción física del paisaje en el que nos desarrollamos, sino también de su significación cultural. Si la sociedad occidental ha apartado los ojos del espacio, en cierta medida los aparta de los vestigios que en él se contienen. Si el espacio sólo se percibe en términos económicos o de la distancia que separa los puntos recorridos en coche, mal se podrá apreciar la dimensión histórica de ese espacio cuyos vestigios evidencian.

Estas y otras circunstancias imposibles de valorar aquí y por nosotros (23) conducen hasta el punto en que mientras la ruptura con la tradición ha permitido separar claramente el pasado del presente y del futuro, el estado nacional, los nacionalismos y todos los procesos discursivos de identidad étnica reinventan una comunidad de sangre y cultura fundamentada sobre un pasado que se pretende común a la nación o a la etnia y distinto al resto. Los vestigios serán la prueba legitimante. Cuando ya se ha roto con la tradición cultural, se inventa la de la historia común. Sus pruebas han de conservarse. Los restos del pasado remoto, que en la sociedad campesina tradicional son la huella del 'otro', se convierten ahora en la marca del 'nosotros' (24).

Desde esta posición el patrimonio se constituye, fundamentalmente, como documento del pasado que nos permite, materializar su existencia, recuperar su memoria y dar significación a sus huellas materiales, los bienes arqueológicos. Esto hace posible que nos aproximemos no a unas raíces extintas, sino al conocimiento de otras gentes y otros mundos que ya no forman parte del nuestro como los 'mouros' en la cultura gallega tradicional. También nos posibilta significar culturalmente un espacio cada vez más anodino al individuo. Efectivamente el patrimonio en la sociedad occidental

(23) Ni nuestra carencia de formación en sociología para analizar la complejidad de la realidad actual ni el espacio disponible lo permiten.

(24) Un ejemplo ilustrador es el trabajo de Mangi (1989:

T. P., 57, n. $^{\circ} 2,2000$ 


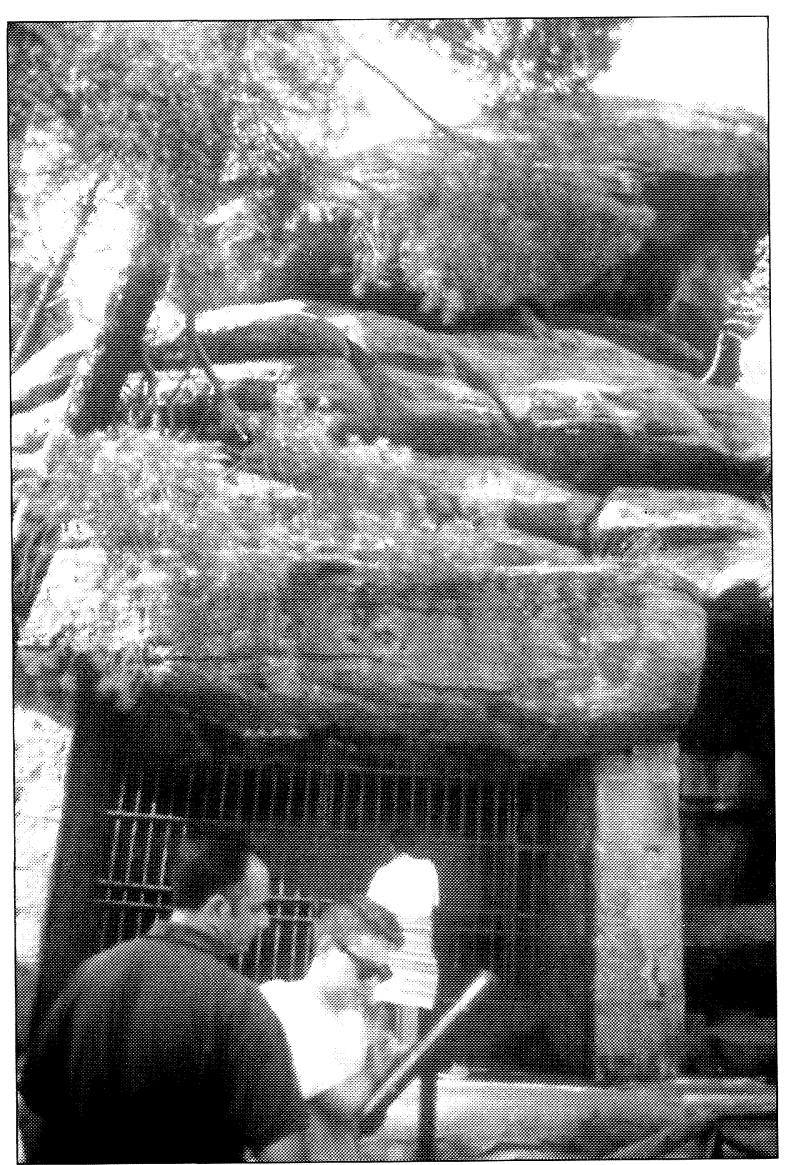

Lám. II. Transmitiendo el sentido del PatrimonioArqueológico al público. Abrigos deAlbarracín (Teruel) significados a través de un discurso textual.

permite amueblar ambas dimensiones: tiempo $y$ espacio.

No obstante, si el interés del PA radica en la penetración del pasado se hace claro que su valoración depende fundamentalmente del conocimiento, no de una tradición cultural o vivencia social que se ha perdido.Y es que siguiendo la propuesta de Levi-Strauss (1964: 374 y ss.; 1987: 60 y ss.) de que la ciencia ocupa en nuestra sociedad la posición que en las primitivas y tradicionales ocupa el mito, mientras éstas integran los restos en su presente en forma de folclore, las sociedades desarrolladas los integran en forma de discurso científico (25) (Lám. II).

(25) Similar afirmación, traducida a coordenadas históricas, ha evidenciado Tilley (1990: 21) quien, asumiendo las mismas propuestas de Levi-Strauss, apunta que el conocimiento histórico y arqueológico es un código para comprender los objetos del discurso que crea y con el que trabaja.
Pero, si la significación del PA depende del conocimiento y trabajo intelectual y éstos apenas se promueven entre la ciudadanía (ni en la educación reglada ni en la educación social en general) hemos de aceptar, desde una perspectiva mínimamente crítica, que el PA no tenga sentido para el público. Admitir esto no es negar el valor del PA, sino situarlo donde realmente se asienta, en la investigación y la divulgación de sus resultados al conjunto social.

\section{EL DESENLACE}

\subsection{El Patrimonio hoy}

En el epígrafe anterior exploramos el PA en la sociedad moderna e industrial. Aunque muchos de sus rasgos se mantienen en la sociedad posindustrial de hoy, otros han variado. Así, antes de que el discurso científico haya llenado el lugar de la tradición, el vacío que ésta deja hoy se llena con la ligereza de la distracción, la laxitud de la vacación o la fuerza de la invención.

$\mathrm{Y}$ es que algunas cualidades del modo de vida actual así lo promueven, pues el público de hoy está: saturado de cultura pero de masas, vacío de tradición pero incrédulo ya de la visión progresiva del devenir histórico (de la noción positiva del cambio), temeroso ante un futuro incierto que hace volverse hacia la preservación de lo que nos rodea y hacia el pasado (conocido y tranquilizador), inmerso en un consumo subyugador, transportado por el poder de la imagen (26), ávido de emociones ligeras, de laxo entretenimiento, etc. Rasgos como éstos dan nuevas utilidades al patrimonio tales como: recurso económico, entretenimiento social e identificador social y cultural.

Sin que estas utilidades sean negativas es preciso disolver el peligro que las acecha, el de ofrecer el patrimonio al mercado como resto material de valores perdidos, como forma vacía, soporte de las últimas técnicas de entretenimiento (Criado y González, 1994; González, 1996). De ahí el interés de aquellos que replican a la pulsión por conservar todos los restos del pasado (cuya utilidad es sacralizar los objetos) en lugar de destruir una parte (con la excavación y estudio) para conservar la memoria, para consolidar a la arqueología como práctica

(26) Nueva tecnología de la comunicación y transmisión del conocimiento aún no valorada en profundidad.

T. P., 57, n. $^{\circ} 2,2000$ 
constructora del conocimiento del 'otro' y del mundo (Criado, 1995: 255) y al PA como elemento que permite pensarlo a la vez que examinarnos a nosotros mismos.

Aquí está el problema actual del patrimonio, en la redefinición de su valor como medio de conocimiento, de semantización del mundo antes que como mero objeto de producción económica o de divertimento.

\subsection{Consecuencias}

Creemos que una estrategia de revalorización del PA debe integrar sus funciones crítica y económica (como significador y como recurso) pues ambas son funciones sociales. Después de discutir aquí la primera, la crítica y reflexiva, se pueden extraer algunas propuestas para significar al PA, que resulte atractivo a la sociedad y que se demande, que sea negocio.

Cuando los bienes arqueológicos se disponen al público, lo que se ofrece, más que la materialidad del vestigio, es una experiencia formada por la conjunción de la contemplación, paseo o cualquier otra forma de contacto con el vestigio, y los valores intelectuales que el observador deriva de este contacto. Estos últimos proceden de sus conocimientos a cerca del vestigio y del momento del que procede. Si partimos de que hoy al pasado remoto nos aproximamos desde el estudio y la investigación distante, a la hora de ofrecer sentido al público es preciso:

- Dotar a los bienes de contexto y significado (Wickham-Jones, 1988: 186-187) (Lám. III). Esto significa ilustrarlos a través de una narrativa, surgida de la investigación y expuesta al público profano de forma comprensible (Criado y González, 1994) (27). Esta narrativa debe dar sentido a los bienes y al momento del que proceden y solventar uno de los problemas del discurso histórico para llegar a la ciudadanía, su atomización en temáticas especializadas múltiples. Su solución pasa por integrar los estudios parciales en narrativas generales que den cuenta de modos de vida pasados.

- Acercar al visitante a la dimensión espacial de los vestigios, pues más que mostrar la sucesión de acontecimientos de la historia (28) se trata de ilus-

(27) Esto es lo que para algunos sería la interpretación del patrimonio.

(28) Esto se puede ver en un libro, no hace falta ir a un parque arqueológico o museo donde se ilustre el PA.

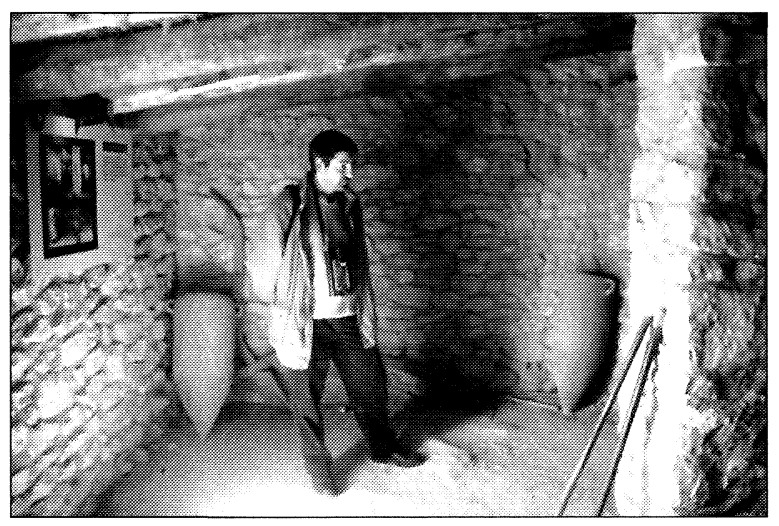

Lám. III. Transmitiendo el sentido del PatrimonioArqueológico al público. Interior de una vivienda perteneciente al poblado ibérico de Calafell (Tarragona) en la que se ha reconstruido parte de su contexto de ocupación: tejado, mobiliario, ajuar...

trar la dimensión social del espacio recuperando su 'lógica' y sentido, significándolo.

Para materializar tales propuestas cualquier fórmula comunicativa vale pero en todo caso defendemos el uso de metodologías y actividades que posibiliten al público cosas tales como: distanciarse y objetivar lo que del pasado se cuenta e incitar a buscar el sentido de lo que se muestra (29).

En la materialización de propuestas de este estilo, conducentes a significar al PA tienen gran protagonismo: (1) los profesionales, pues son reconocidos por el público como sus más próximos investigadores y dadores de sentido; (2) los modernos métodos de comunicación y transmisión social del saber: la informática y medios audiovisuales.

Si con la escritura y la historia tenemos una manera, distinta de la oralidad, para ordenar y explicar el pasado, es previsible que con los nuevos procedimientos de transmisión social del saber se vuelva a modificar. Aunque sus efectos son poco conocidos por recientes, la información en tiempo real, la imagen como fórmula de acceso al pasado, la realidad virtual para re-construir e ilustrar los vestigios, etc., probablemente den un nuevo vuelco a la manera de aproximarse y entender el patrimonio (30). Los profesionales hemos ser conscientes del papel de ambos (profesionales y medios de comunicación) para conjugar procedimientos y demandas sociales y patrimoniales.

(29) La recuperación de la oralidad en la transmisión de sentido puede ser una buena fórmula, pues aunque más costosos, el público prefiere guías y comunicadores a las formas escritas.

(30) Una discusión de tal temática se ofrece en Bermejo (1998).

T. P., 57, n. ${ }^{\circ} 2,2000$ 


\section{AGRADECIMIENTOS}

A Felipe Criado que discutió e inspiró muchas ideas de este texto.

\section{BIBLIOGRAFÍA}

Alegre Ávila, J.M. (1994): Evolución y régimen jurídico del Patrimonio Histórico. Ministerio de Cultura. Madrid, vol. 1.

Álvarez Álvarez, J.L. (1997): "El Patrimonio Cultural. De dónde venimos y a dónde vamos". Patrimonio Cultural y Derecho, 1: 15-31.

ANTONA DEL VAL, V. (coord.)(1994): Jornadas sobre Patrimonio. Fundación Cultural Banesto. Madrid.

Barrero Rodríguez, C. (1990): La ordenación jurídica del Patrimonio Histórico. Civitas. Madrid.

Bermejo BARRERA, J.C. (1987): El final de la historia. Ensayos de historia teórica. Akal Univeristaria. Madrid.

- (1998): "La historia como sistema de comunicación". Gallaecia, 17: 351-368.

BARRIL Vicente, M. (1996): "Los museos y la presentación de la arqueología. Perspectiva social de Futuro". En M.A. Querol y T. Chapa (eds.): Homenaje al Profesor M. Fernández Miranda. Complutum extra, 6 (1): 317 327.

Clastres, P. (1996): Investigaciones en antropología política. Gedisa. Barcelona.

Cleere, H. (1989): "Introduction: The rationale of archaeological heritage management". En H. Cleere (ed.): Archaeological heritage management in the modern world. Unwin Hyman. Londres: 1-19.

CostA, B.; FernÁNDEZ, J.H. y HoYos, R.Mª de (1996): “La ley $16 / 1985$ y la defensa del patrimonio arqueológico en Ibiza: el caso de Can Partit". En M.A. Querol y T. Chapa (eds.): Homenaje al Profesor M. Fernández Miranda. Complutum extra, 6 (1): 369-381.

CRAIG, B. (1989): "Interpreting the historic scene: The power of imagination in creating a sense of historic place”. En D.L. Uzzell (ed.): Heritage interpretation 1. Belhaven Press. Londres: 107-112.

Criado BoAdo, F. (1986): "Serpientes gallegas: madres contra rameras". En J.C. Bermejo (dir.): Mitología y mitos de la Hispania prerromana, 2. Akal Universitaria. Madrid: 241-274.

- (1988): "Arqueología del paisaje y espacio megalítico en Galicia”. Arqueología Espacial, 12: 61-117.

- (1989a): "El passat segons el poder: Alternatius, policies y arqueòlegs a Stonehenge". Cota Zero, 5: 109-14.

- (1989b): "Megalitos, espacio, pensamiento".Trabajos de Prehistoria, 46: 75-98.

- (1993): "Límites y posibilidades de la arqueología del paisaje". SPAL, 2: 9-55.

- (1995): "El control arqueológico de obras de trazado lineal: planteamientos desde laArqueología del Paisaje". En Actas del XXII Congreso Nacional deArqueología (Vigo, 1993), 1: 261-266. Vigo.

Criado Boado, F. y González Méndez, M. (1994): "La puesta en valor del patrimonio arqueológico desde la perspectiva de la arqueología del paisaje". Conservación arqueológica. Reflexión y debate sobre teoría y práctica. Cuadernos del Instituto Andaluz del Patrimonio Histórico, 3: 58-75.

DARVILL, T. (1993): Valuin Britain's archaeological resource. Universidad de Bournemouth. Bournemouth.

Dumont, L. (1989): La civilización india y nosotros. Alianza. Madrid.

DURALDE, J. R. (1995): "Patrimonio de propiedad privada: un interés de todos". Restauración \& Rehabilitación: 2: 35-7.

Foucault, M. (1981): Un diálogo sobre el poder. Alianza. Madrid.

- (1985): Saber y verdad. Las ediciones de la Piqueta. Madrid.

- (1988a): Las palabras y las cosas. Una arqueología de las ciencia's humanas. Siglo XXI. Madrid.

- (1988b): La arqueología del saber. Siglo XXI. Madrid.

GonZÁlez MÉnDEZ, M. (1996): "Viajes a vestigios. Incitación del consumo a la arqueología". Difusión del Patrimonio. Cuadernos del Instituto Andaluz del Patrimonio Histórico, 7: 44-59.

- (1999): Investigación y puesta en valor del Patrimonio Histórico: Planteamientos y propuestas desde la Arqueología del Paisaje. Universidad de Santiago. Santiago de Compostela (publicación en CD).

- (2000): "El contexto legal del patrimonio arqueológico en Galicia y su disposición para la gestión y revalorización". Gallaecia, 19: 381-406.

Goody, J. (1985): La domesticación del pensamiento salvaje. Akal. Madrid.

- (1987): The interface between the written and the oral. Cambridge University Press. Cambridge.

- (1996) (comp.): Cultura escrita en sociedades tradicionales. Gedisa. Barcelona.

- (1999): Representaciones y contradicciones. Paidós. Barcelona.

Goody, J. y W ATT, I. (1996): "Las consecuencias de la escritura". En J. Goody (comp.): Cultura escrita en sociedades tradicionales. Gedisa. Barcelona: 39-82.

Llinares García, M. (1990a): Os mouros no imaxinario popular galego. Universidad de Santiago de Compostela. Santiago de Compostela.

- (1990b): Mouros, ánimas, demonios. El imaginario popular gallego. Akal. Madrid.

Levi-STRauss, C. (1964): El pensamiento salvaje. Fondo de Cultura Económica. Méjico.

- (1986): La alfarera celosa. Paidos. Barcelona.

- (1987): Mito y significado. Alianza. Madrid.

- (1991): El hombre desnudo. Mitológicas IV. Siglo XXI. Madrid. 
Lorite Mena, J. (1995): Sociedades sin Estado. El pensamiento de los otros. Akal. Madrid.

Lowenthal, D. (1981): "Conclusion: Dilemmas of preservation." En D. Lowhental y M. Binney (Eds): Our past before us: Why do we save it?. Temple Smith. Londres: 213-237.

- (1998): El pasado es un país extraño. Akal. Madrid.

Mamami Condori, C. (1989): "History and prehistory in Bolivia: what about the indians?". En R. Layton (ed.): Conflict in the archaeology of living traditions. Unwin Hyman. Londres: 46-59.

MANGI, J. (1989): "The role of archaeology in nation building”. En R. Layton (ed.): Conflict in the archaeology of living traditions. Unwin Hyman. Londres: 217-27.

Merrimam, N. (1988): "The Heritage industry reconsidered". Archaeological Review from Cambridge, 7 (2): 146-156.

Querol Fernández, M.A. y Martínez DíAz, B. (1996): La gestión del patrimonio arqueológico en España. Alianza. Madrid.

Querol Fernández, M.A.; Martínez Navarrete, M. ${ }^{\mathrm{a}}$.; Hernández, F.; Cerdeño, L. y Antona, V. (1995): “The value of archaeological heritage: an analysis by the Professional Association of Spanish Archaeologist (APAE)". Journal of European Archaeology, 3 (1): 233-246.

SAUNDERS, A. (1989): "Heritage management and training in England". En H. Cleere (ed.): Archaeological heritage management in the modern world. Unwin Hyman. Londres: 152-163.

Shanks, M. y Tilley, C. (1987): Re-constructing archaeology. Routledge. Londres.

TILLEY, C. (1989): “Archaeology as a sociopolitical action in the present". En V. Pinsky (ed.): Critical traditions in contemporary archaeology. Cambridge University Press. Cambridge: 104-116.

- (1990): "Constituint una arqueologia social: un projecte modernista". En J. Anfruns y E. Llobet (eds.): El canvi cultural a la prehistòria. Columna. Barcelona: 1742.

VicENT GARCíA, J.M. (1990): "El neolític: transformacions socials i económiques". En J. Anfruns y E. Llobet (eds.): El canvi cultural a la prehistòria. Columna. Barcelona: 241-293.

WALSH, K. (1992): The representation of the past. Routledge. Londres.

- (1995): "A sense of place. A role for cognitive mapping in the posmodern world?". En I. Hooder, M. Shanks, A. Alexandri, V. Buchli, J. Carman, J. Last y G. Lucas (eds.): Interpreting archaeology. Routledge. Londres: 131-8.

WiCKMAN-Jones, C.R. (1988). "The road to Heri-Tat: Archaeologist and interpretation".Archaeological Review from Cambridge, 7 (2): 185-193.

WoLf, E. (1982): Los campesinos. Barcelona. Labor. 